\title{
CHARACTERISATION OF BACTERIAL ISOLATES FROM INFECTED BURN WOUNDS OF PATIENTS ADMITTED IN A TERTIARY LEVEL HEALTH CARE FACILITY IN NORTHERN REGION OF INDIA.
}

Antariksh Deep, Pooja Singla, Rama Sikka Menal Gupta, Uma Chaudhary

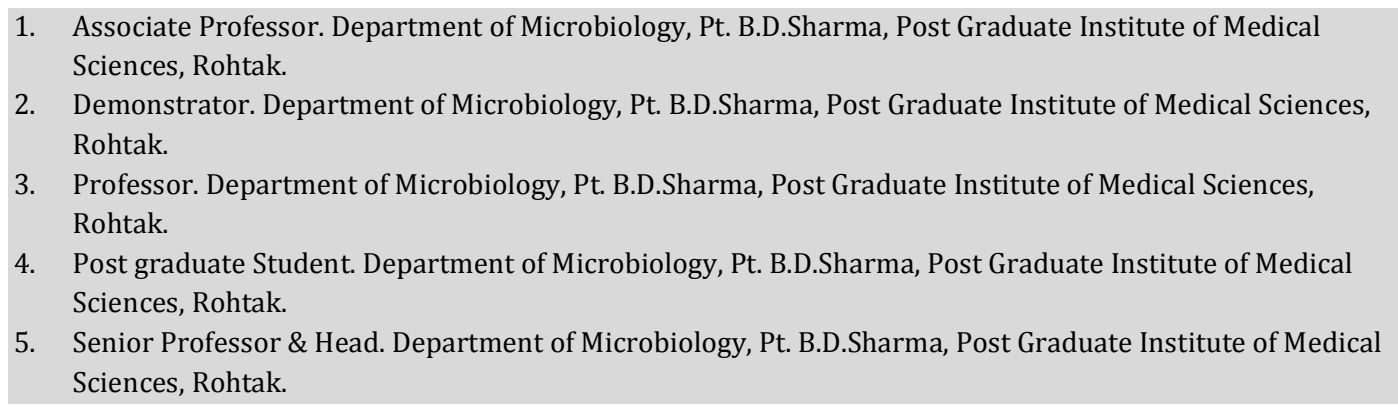

\section{CORRESPONDING AUTHOR:}

Dr. Antariksh Deep,

Associate professor,

Department of Microbiology,

Pt. B.D.Sharma, Post Graduate Institute

of Medical Sciences, Rohtak.

E-mail: drantarikshdeep@hotmail.com

ABSTRACT: Infection is an important cause of mortality in burns. Emergence of multi drug resistant pathogens in hospital setting has seriously constrained the available therapeutic options. This necessitates periodic review of the isolation pattern and study of antibiogram of the isolates to strengthen surveillance activities.

To determine the bacteriological profile and antimicrobial susceptibility pattern of pathogens isolated from infected burn wounds of patients admitted in the burns care unit. The present study was carried out over a duration of six months. Pus samples from infected burn wounds were processed following standard protocols. Antimicrobial susceptibility of the bacterial isolates was performed by Kirby- Bauer disc diffusion method. A total of 408 bacterial pathogens were isolated from 340 samples. The most frequent cause of infection was found to be Pseudomonas aeruginosa (53\%), followed by Staphylococcus aureus (9\%), Escherichia coli (9\%), Enterobacter spp. (8\%), Citrobacter spp. (8\%), Klebsiella spp. (5\%), Acinetobacter spp. (3\%) and Proteus spp. (3\%). High level of drug resistance (95-100\%) was observed for cefepime, ceftazidime, amoxyclav, cotrimoxazole and doxycycline among gram negative pathogens. Meropenem, amikacin and ciprofloxacin were found to be most effective. Twenty one percent of the $\mathrm{S}$. aureus isolates were resistant to methicillin. The high prevalence of antimicrobial resistance emphasizes the need for strengthening the infection control practices and regular and periodical surveillance activities to contain the upward trend of resistance.

KEYWORDS: Burn wounds, Surveillance, Antimicrobial resistance, Infection control programme.

INTRODUCTION: Burn wounds are still the most common and devastating forms of thermal injury. ${ }^{1}$ With the advancement in medical care and advent of specialized burns treatment facilities, the survival rate of patients with extensive burn wounds has improved substantially. 
Despite this, the burn wound sepsis is still an important complication in this group of patients. ${ }^{2}$ This is due to the unique pathophysiologic mechanisms operating in the burn wound patients. The breach in the intact human skin lining leads to disturbances in the body fluid homeostasis, thermoregulation and potentially serious immune suppression. As a result of thermal injury to skin, there is large scale release of various cytokines, prostaglandins and leukotrienes which leads to suppression of the immune response. In addition to this, the presence of avascular devitalized tissue, provides an excellent environment for colonisation of wounds by microorganisms, which can on finding an opportune moment lead to burn wound infection. ${ }^{3}$ The situation gets aggravated when the environment in the burns care unit gets contaminated with multi-drug resistant organisms. Keeping all these factors in mind, a well organized surveillance system coupled with good infection control practices can go a long way in reducing the incidence of burn wound infections. The present study was undertaken to know the antimicrobial susceptibility profile of various bacterial isolates recovered from patients of infected burn wounds which will help in instituting empirical therapy and minimize irrational use of higher antimicrobial agents.

MATERIAL AND METHODS: The present retrospective study was carried out in the Department of Microbiology, Pt. B.D. Sharma, Post Graduate Institute of Medical Sciences, Rohtak, a tertiary level health care providing facility in northern region of India, over a period of six months, i.e. from $1^{\text {st }}$ July 2012 to $31^{\text {st }}$ December 2012. All the patients admitted in the Burns care Unit of the hospital with total burns surface area more than $20 \%$, irrespective of the age and gender differences were included in the study. The burn wound infections were diagnosed by quantitative cultures, in presence of pathognomic clinical appearance of the wound. Isolation and identification of the organisms was done following the standard protocol. ${ }^{4}$ The antimicrobial susceptibility testing of the isolates was carried out by Kirby Bauer disk diffusion method, following the CLSI guidelines using commercially available antimicrobial disks procured from the HI-MEDIA Laboratories Pvt. Ltd., Mumbai. ${ }^{5}$

OBSERVATIONS: In all, over a period of six months, pus samples from infected wounds of a total of 485 burns patients were received in the laboratory and processed further. Out of these samples, 340 samples yielded significant growth of bacterial isolates. Out of these polymicrobial infections was observed in 30 patients. A total of 408 bacterial isolates were obtained.

The pattern of distribution of the isolates is summarized in the table no. 1 and 2.

Table 1. The distribution of bacterial isolates from infected burn wounds

\begin{tabular}{|c|c|}
\hline ORGANISM & TOTAL NO. OF ISOLATES,n=408 (\%) \\
\hline Pseudomonas aeruginosa & $217(53)$ \\
\hline Staphylococcus aureus & $38(09)$ \\
\hline Escherichia coli & $36(09)$ \\
\hline Enterobacter spp. & $34(08)$ \\
\hline Citrobacter spp. & $34(08)$ \\
\hline Klebsiella spp. & $22(05)$ \\
\hline Acinetobacter spp. & $14(03)$ \\
\hline Proteus spp. & $13(03)$ \\
\hline
\end{tabular}


Table 2. The distribution of bacterial isolates in cases with Polymicrobial flora

\begin{tabular}{|c|c|}
\hline Combination of organisms (Total 30 ) & No. of cases \\
\hline $\begin{array}{c}\text { Pseudomonas aeruginosa } \\
+ \\
\text { Staphylococcus aureus }\end{array}$ & 12 \\
\hline $\begin{array}{c}\text { Pseudomonas aeruginosa } \\
+ \\
\text { Proteus species } \\
+ \\
\text { Staphylococcus aureus }\end{array}$ & 08 \\
\hline $\begin{array}{c}\text { Pseudomonas aeruginosa } \\
+ \\
\text { Citrobacter species }\end{array}$ & 05 \\
\hline $\begin{array}{c}\text { Pseudomonas aeruginosa } \\
+ \\
\text { Escherichia coli }\end{array}$ & 05 \\
\hline
\end{tabular}

The susceptibility profile of the organisms to various antimicrobial agents is summarized in the tables 3 , 4, and 5 .

Table 3. Antibiogram of Gram negative isolates other than Pseudomonas aeruginosa

\begin{tabular}{|c|c|c|c|c|c|c|c|c|}
\hline $\begin{array}{l}\text { Antimicrobial } \\
\text { Isolate }\end{array}$ & 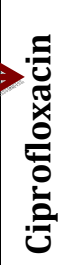 & 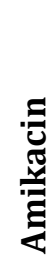 & 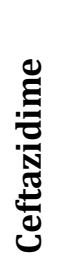 & 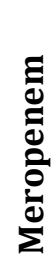 & 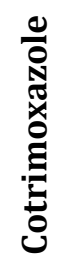 & 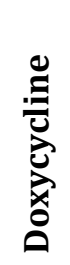 & : & 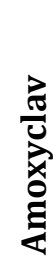 \\
\hline Escherechia coli & 33 & 33 & 00 & 44 & 00 & 00 & 06 & 00 \\
\hline Enterobacter spp. & 35 & 38 & 00 & 38 & 00 & 00 & 00 & 00 \\
\hline Citrobacter spp. & 29 & 44 & 03 & 47 & 00 & 00 & 00 & 00 \\
\hline Klebsiella spp. & 18 & 32 & 00 & 23 & 00 & 00 & 05 & 00 \\
\hline Acinetobacter spp. & 36 & 36 & 00 & 36 & 21 & 07 & 00 & 00 \\
\hline Proteus spp. & 15 & 31 & 00 & 23 & 00 & 00 & 00 & 00 \\
\hline
\end{tabular}

Table 4. Antibiogram of Pseudomonas aeruginosa

\begin{tabular}{|c|c|c|c|c|c|c|c|c|}
\hline $\begin{array}{c}\text { Antimicrobial } \longrightarrow \\
\qquad \\
\text { Isolate }\end{array}$ & 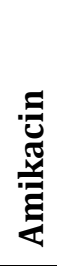 & 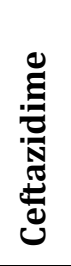 & 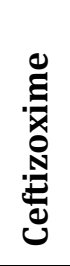 & 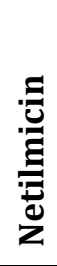 & 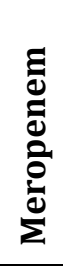 & 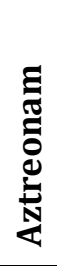 & 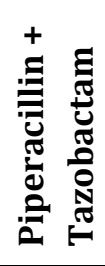 & 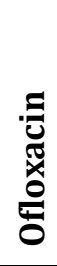 \\
\hline Pseudomonas aeruginosa & 23 & 01 & 02 & 12 & 23 & 05 & 36 & 12 \\
\hline
\end{tabular}


Table 5. Antibiogram of Staphylococcus aureus

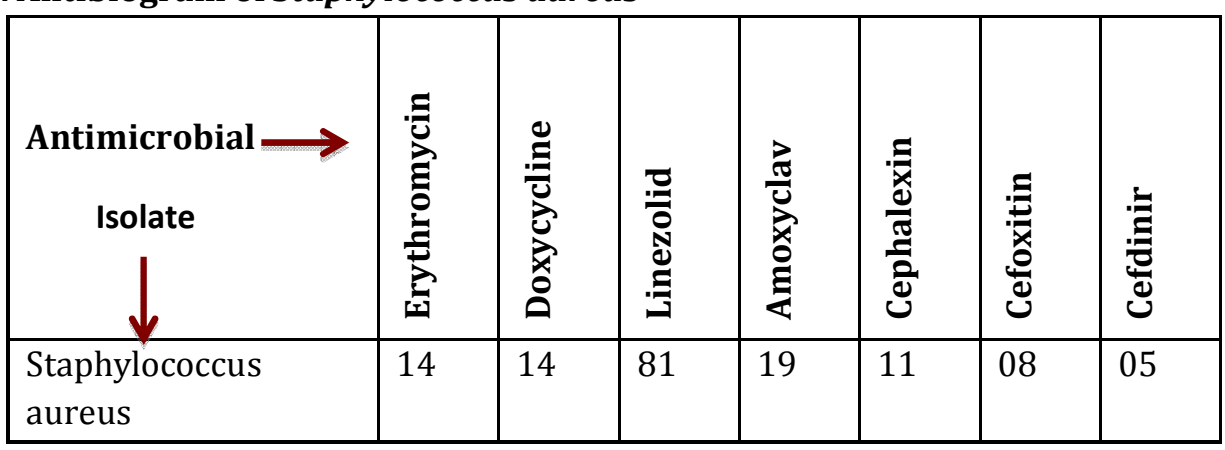

DISCUSSION: Immediately following the thermal injury, the burn wounds are sterile; but eventually get colonised with microorganisms. ${ }^{6}$ Staphylococci, that are present deep within sweat glands and hair follicles colonise the wound surface within the first $48 \mathrm{hrs}$. After 5-7 days, the GNBs' and yeasts derived from the host's normal GI flora, upper respiratory tract and the hospital environment get transferred to the wounds through HCWs' hands. ${ }^{7}$ In our study, Pseudomonas aeruginosa was the commonest organism isolated, accounting for $53 \%$ of the total isolates. This was followed by the Staphylococcus aureus which accounted for $38 \%$ of the total isolates. Similar results have been reported from both Indian as well as foreign studies.8,9 The rate of isolation of other commonly encountered nosocomial pathogen in high antimicrobial pressure areas of the hospital environment, i.e. Acinetobacter baumanniiwas surprisingly quite less, i.e. $14 \%$ in our study. Similar results have been documented in the study from Chandigarh. 3 However, in the study from Turkey, Acinetobacter spp. Constituted the second commonest organism (21\%), after Pseudomonas aeruginosa (57\%). ${ }^{10}$

A very high rate of antimicrobial resistance was seen in this study across all bacterial isolates, even to the higher antimicrobial agents. This is in sharp contrast to other studies, reported from developing countries like Iran and Turkey. ${ }^{9,11}$ However, a high rate of resistance to commonly used antimicrobial agents was reported in a study from Chandigarh, and also from Nigeria.8,10 The possible explanation that can be attributed to the high prevalence of antimicrobial resistance in this Institute could be that most of the patients admitted in this Institute are referred from some other treating facility where they have already received some antimicrobial agents. The injudicious panaceas offered at the peripheral centres further complicate the already grim situation.

CONCLUSION: The high rate of resistance, even to the high end antimicrobial agents seen across all the bacterial isolates in our study is an emerging troublesome fact. This underscores the need for strengthening the infection control practices and regular and periodical surveillance activities to contain the upward trend of resistance. Perhaps, novel strategies have to be explored in this scenario where the available options in the armamentarium of antimicrobial agents are continuously shrinking. One such strategy to have been reported is using combination of oral antimicrobials to control the GI reservoir for suppression /elimination of microorganisms, termed, "selective intestinal decontamination (SDD)."12Also, admission surveillance cultures should be done to screen patients with colonisation by antibiotic resistant organisms. Strict enforcement of infection control practices and antimicrobial rotation programmes can go a long way in reducing the burden of multi-drug resistant organisms. 


\section{REFERENCES:}

1. Deirdre Church,Sameer Elsayed,Owen Reid,Brent Winston,and Robert Lindsay. Burn Wound Infections Clinical Microbiology Reviews, Apr. 2006, p. 403-434.

2. O'Sullivan ST, O'Connor TPF. Immunosuppression following ther- mal injury: the pathogenesis of immunodysfunction. Br J PlastSurg1997; 50:615-23.

3. Mooney DP, Gamelli RL. Sepsis following thermal injury. ComprTher1989; 15:22-9.

4. The nonfermentative gram-negative bacilli. In: Winn Jr. WC, Allen SD, Janda WM, Koneman EW, Procop GW, Schreckenberger PC, et al, editors. Koneman's color Atlas and Textbook of Diagnostic Microbiology, $6^{\text {th }}$ ed. Philadelphia: Lippincott Williams and Wilkins; 2006.p.303-391.

5. Clinical and Laboratory Standards Institute. Performance standards for antimicrobial disk susceptibility tests: approved standard. 9th ed. CLSI document M2-A9, Vol 26(1). Wayne, PA; 2006.

6. Erol, S., U. Altoparlak, M. N. Akcay, F. Celebi, and M. Parlak. 2004. Changes of microbial flora and wound colonization in burned patients. Burns 30:357-361.

7. Altoparlak, U., S. Erol, M. N. Akcay, F. Celebi, and A. Kadanali.2004. The time-related changes of antimicrobial resistance patterns and predominant bacterial profiles of burn wounds and body flora of burned patients. Burns 30:660-664.

8. Manjula Mehta, PriyaDutta, Varsha Gupta. Bacterial isolates from burn wound infections and their antibiograms: A eight-year study. Indian J PlastSurg Jan-June 2007;40(1);2528.

9. AlirezaEkrami\&EnayatKalantar. Bacterial infections in burn patients at a burn hospital in Iran. Indian J Med Res 126, December 2007, pp 541-544

10. Kehinde A.O., Ademola S.A., Okesola A.O., Oluwatosin O.M., Bakare R.A.Pattern of Bacterial Pathogens In Burn Wound Infections In Ibadan, Nigeria. Annals Of Burns And Fire Disasters.2004 Vol. XVII - N. 1.

11. O. Oncul, E. UlkurA. Acar, V. Turhan, E. Yeniz, Z. Karacaer\& F. Yildiz. Prospective analysis of nosocomial infections in a Burn Care Unit, Turkey. ndian J Med Res 130, December 2009, pp 758-764.

12. C. Glen Mayhall. The Epidemiology of Burn Wound Infections: Then and Now Clinical Infectious Diseases 2003;37:543-50. 